\title{
Soluções projetuais do Arquiteto Milton Monte para Amazônia no contexto da sustentabilidade
}

Architectural Milton Monte's design solutions for the Amazon in the context of sustainability

Soluciones de diseño arquitectónicas de Milton Monte para la Amazonía en el contexto de la sostenibilidad

Hugo Felipe de Souza Arraes Graduando, UFPA, Brasil. felipe.arraes99@gmail.com

Ana Kláudia de Almeida Viana Perdigão Professora Doutora, UFPA, Brasil. klaudiaufpa@gmail.com 


\title{
Revista Científica ANAP Brasil
}

\author{
ISSN 1984-3240 - Volume 13, número 30, 2020
}

\section{RESUMO}

A sustentabilidade mostra-se na obra de Milton Monte com a busca de produção arquitetônica relacionada aos aspectos ambientais e culturais da Amazônia. Desse modo o estudo da trajetória do arquiteto e suas decisões projetuais permite uma melhor compreensão dos fundamentos de uma arquitetura comprometida com o lugar amazônico. Este artigo apresenta a produção arquitetônica na Amazônia por meio de um arquiteto de grande importância na medida em que tornou possível um vocabulário único em suas obras que podem traduzir um pensamento projetual refinado para apresentar uma linguagem de projeto que demonstra a identidade profissional do Arq. Milton Monte como uma alternativa a ser utilizada no ensino como referência operativa prática. Para isso, foi realizada uma breve sistematização da trajetória do arquiteto e uma análise que busca na sua produção a intencionalidade de se vincular sua obra ao lugar amazônico. Os esquemas e análises apresentaram puderam atestar a criação de uma arquitetura correlacionada ao lugar amazônico e de grande operação cognitiva.

PALAVRAS-CHAVE: Projeto. Milton Monte. Amazônia.

\section{ABSTRACT}

Sustainability is in Milton Monte's work with the search for architectural production related to culture and adaptation to the climate of the Amazon region. In this way, the study of the architect's trajectory and his design decisions allows a better understanding of the fundamentals of an architecture committed to the Amazonian place. This article presents the architectural production in the Amazon through an architect of great importance in that it made possible a unique vocabulary in his works that can translate a refined design thinking to present a design language that demonstrates the professional identity of Arch. Milton Assemble as an alternative to be used in teaching as a practical operational reference. For this, a brief systematization of the architect's trajectory was carried out and an analysis that seeks in his production the intention of linking his work to the Amazonian place. The schemes and analyzes presented could attest to the creation of an architecture correlated to the Amazonian place and of great cognitive operation.

KEYWORDS: Project. Milton Monte. Amazon.

\section{RESUMEN}

La sustentabilidad se muestra en el trabajo de Milton Monte con la búsqueda de la producción arquitectónica relacionada con la cultura y la adaptación al clima de la región amazónica. De esta forma el estudio de la trayectoria del arquitecto y sus decisiones de diseño permite comprender mejor los fundamentos de una arquitectura comprometida con el lugar amazónico. Este artículo presenta la producción arquitectónica en la Amazonía a través de un arquitecto de gran importancia por cuanto ha hecho posible un vocabulario único en sus obras que puede traducir un refinado pensamiento de diseño para presentar un lenguaje de diseño que demuestre la identidad profesional de Arch. Milton Ensamblar como alternativa para ser utilizado en la enseñanza como referencia operativa práctica. Así, se realizó una breve sistematización de la trayectoria del arquitecto y un análisis que busca en su producción la intención de vincular su obra al lugar amazónico. Los esquemas y análisis presentados podrían dar fe de la creación de una arquitectura correlacionada con el lugar amazónico y de gran funcionamiento cognitivo.

PALABRAS CLAVE: Proyecto. Milton Monte. Amazonas. 


\section{Revista Científica ANAP Brasil}

ISSN 1984-3240 - Volume 13, número 30, 2020

\section{INTRODUÇÃO}

A América Latina tem sido palco de uma vasta produção arquitetônica com repetições de fórmulas internacionais. No Brasil não é diferente; com seu amplo território e regiões com diferentes realidades geográficas, históricas e culturais - via de regra, a produção de arquitetura muitas vezes não dialoga efetivamente com as condicionantes locais. Na Amazônia torna-se ainda mais desafiador enfrentar o conflito entre o pensamento hegemônico da arquitetura e os modos de morar próprios de um padrão cultural da região (PERDIGÃO et al, 2018). Por outro lado, o projeto de arquitetura se apresenta cada vez mais complexo e exige mais aprofundamento de conhecimento profissional em torno das decisões arquitetônicas em pauta. Não é de hoje que há destaque para uma crise do ensino de arquitetura, uma crise da disciplina arquitetura e urbanismo (COMAS, 1986). A inexistência de uma disciplina projetual cientificamente estruturada e a configuração pedagógica adequada criam uma diferença entre o aprender arquitetura e o aprender a fazer arquitetura (SILVA, 1986), o que fica evidente na distinção pedagógica adotada entre disciplinas teóricas e práticas a qual interfere no poder de síntese, entendida como uma operação mental de grande relevância na disciplina de projeto; Zein (2003) aponta que a síntese será obtida quando o ateliê for transformado em disciplina teórico-prática.

Assim sendo, o ensino e a pesquisa em projeto mostram-se de fundamental importância e juntos funcionam como um indutor de reflexão e de especulação, podendo com isso produzir uma condição arquitetônica mais alinhada com um pensamento projetual condizente com a realidade local, o que marcadamente encontra-se na trajetória de arquitetos comprometidos com o lugar. Desse modo, a sustentabilidade se mostra um conceito que dialoga com o respeito ao lugar, permitindo uma abordagem mais ampla sobre as decisões projetuais que marcam a intencionalidade do arquiteto em fazer sua arquitetura incidir diretamente sobre o bioclima amazônico, explicitando a busca na cultura local de soluções que já façam parte do cotidiano do homem amazônico.

O Arquiteto Milton Monte foi selecionado para investigação de uma abordagem projetual sobre a Amazônia por apresentar um modo muito particular de produzir arquitetura através de um vocabulário arquitetônico único, a Arquitetura do Barracão (MONTE, 1988; PERDIGAO et al 2018). O Arquiteto nasceu em Xapuri (Acre) no ano de 1928, seus escritos relatam sua história de vida como uma inspiração para os próprios projetos, na sua infância manteve contato com o barracão seringalista e o modo de vida do seringal bem como, posteriormente, com uma habitação indígena em exposição na cidade de Belém (PA), cidade esta que acolheu sua família e onde se formou como engenheiro em 1952. Formou-se na primeira turma de arquitetura em 1964, uma continuidade de dois anos de curso para formação de uma turma de engenheiros.

A vida acadêmica transcorreu também como professor do recém-criado Curso de Arquitetura da Universidade Federal do Pará para o qual foi convidado a lecionar, bem como aluno até a conclusão do Curso de Especialização "Arquitetura nos Trópicos"; onde desenvolveu uma monografia intitulada "Estudos e contribuições de projetos de edificações na Amazônia Equatorial", documento de grande relevância para futuras gerações de arquitetos na Região Amazônica. Para Segawa (2005) Milton Monte é apontado como um exemplo de uma geração de arquitetos amazônicos que buscam uma produção mais relacionada à cultura local e a uma adequação formal ao clima e cultura da região amazônica. 
Busca-se investigar e disseminar aspectos do conjunto da obra de Monte para oferecer uma melhor compreensão dos fundamentos de uma arquitetura comprometida com o lugar amazônico. Os resultados de pesquisa trazem contribuições para um conhecimento operativo da arquitetura mais voltado às peculiaridades da Região Amazônica, fortalecendo a análise que orienta a síntese arquitetônica e demonstrando a importância das teorias de produção arquitetônica para oferecer melhorias à prática projetual, reveladas mais fortemente com a pesquisa em projeto.

\section{OBJETIVOS}

Objetiva-se demonstrar em que medida o modo de projetar do Arquiteto Milton Monte se relaciona com aspectos culturais da Região Amazônica, e de que maneira os elementos de sua arquitetura podem contribuir para fortalecer o pensamento projetual na formação do arquiteto.

\section{METODOLOGIA}

Esse artigo traz parte dos resultados de pesquisa referentes a um plano de iniciação científica, intitulado "o conhecimento operativo implícito na trajetória do Arquiteto e Professor Milton Monte para Amazônia". A metodologia utilizada foi Pesquisa bibliográfica; análise de projetos de arquiteto Milton Monte, entrevistas e relatos de clientes, amigos e familiares do arquiteto; e, sistematização de elementos físico-espaciais presentes na sua obra.

\section{RESULTADOS}

A preservação de uma diversidade de modos culturais de se fazer arquitetura existentes (GUY; FARMER, 2001 apud SANTOS, COSTA, 2017) está associada à abordagem discutida com a trajetória profissional do Arquiteto Milton Monte, ou seja, de uma sustentabilidade arquitetônica mais ligada ao conceito eco-cultural conforme Costa e Santos (2017). Portanto, a obra de Monte mostra-se como uma arquitetura erudita que utilizou o espaço e a ecologia cultural como fonte de conhecimento, repercutindo em uma noção de uso de tecnologias próximas do local frente à massiva padronização internacional.

A sustentabilidade arquitetônica baseada na lógica conceitual ecocultural propõe justamente a resistência ao fenômeno de homogeneização da Cultura Moderna (GUY; FARMER, 2001). Entretanto, pontua-se que os aspectos da Globalização, que cria novas identidades (híbridas), fazem com que essa dimensão cultural do habitar, da moradia, não fique restrita ao contexto do construtor vernacular e de sua comunidade, pois as soluções projetuais, tecnologias construtivas e de uso do material vêm sendo, ao longo do processo de constante (re)produção do espaço construído, incorporados às práticas construtivas tradicionais como soluções sinônimas de Sustentabilidade Arquitetônica. (Santos, Costa, 2017. Pg. 227-228).

Além da memória e recorrente utilização de elementos bem marcados do barracão seringalista da Amazônia em sua obra (ver figura 1), Monte (1986) relatou sua experiência de observação, 


\section{Revista Científica ANAP Brasil}

ISSN 1984-3240 - Volume 13, número 30, 2020

em 1976, na cidade Belém, da residência indígena Waiãpi (Ver Figura 2) e cita como nela continham estratégias e soluções formais que melhoravam a temperatura interna, destacando seus aspectos construtivos, principalmente sua cobertura e beirais. Foi com base na observação do funcionamento da residência Waiãpi que Monte criou o beiral quebrado, sendo sua residência de veraneio também um laboratório de experimentações (ver figura 3). Trata-se de uma solução adotada para impedir a incidência de raios solares e para permitir o controle da iluminação e ventilação no interior da edificação (PERDIGAO, 1994).
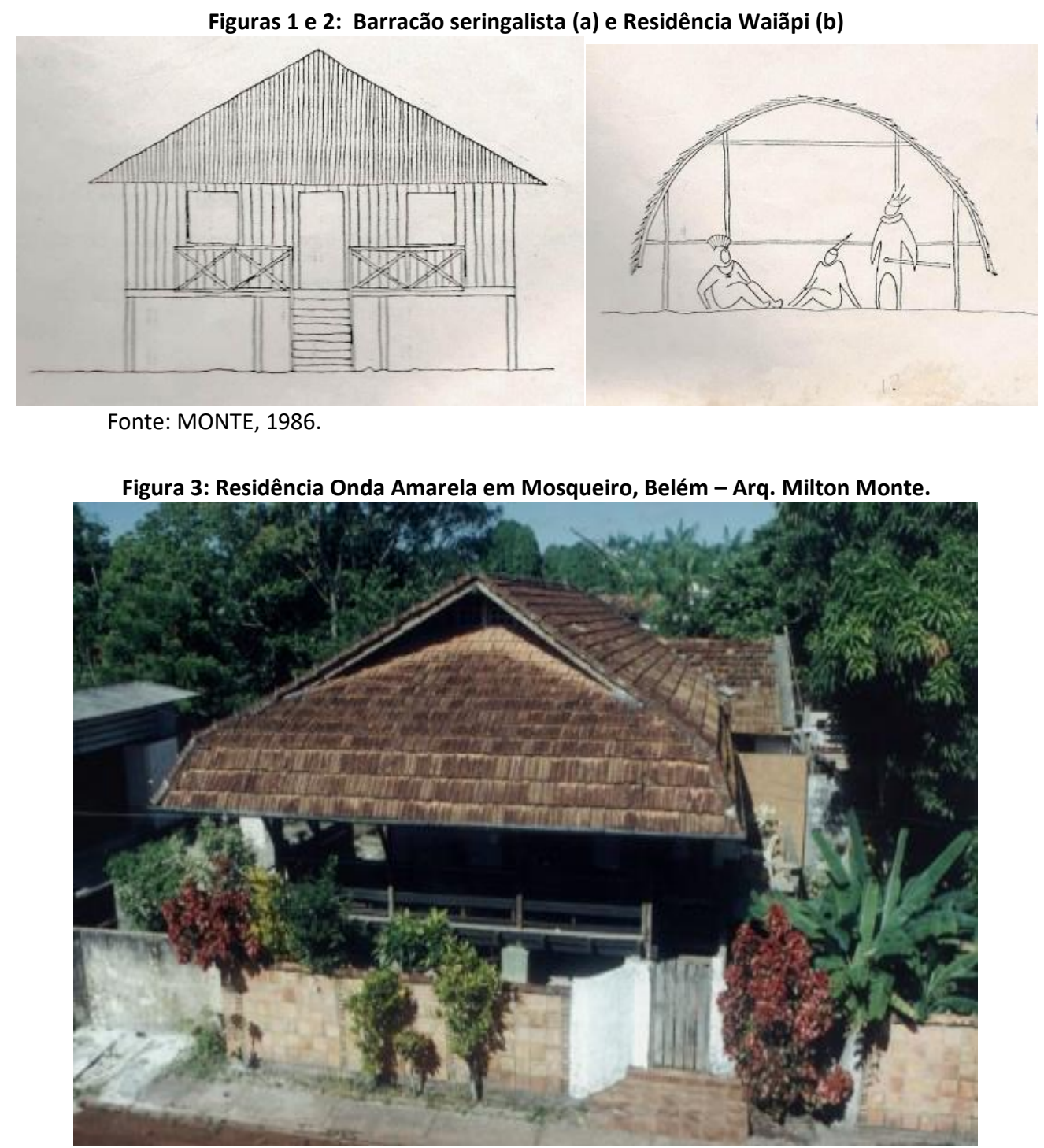

Fonte: Acervo LEDH (2018), cedido por familiares.

Para Perdigão (1997) a arquitetura de Monte demonstra o desenvolvimento e a aplicação ao projeto de arquitetura de princípios bioclimáticos apropriados à região amazônica com base em requisitos elaborados por Villas-Boas (1985) sobre arquiteura tropical brasileira. A autora (1997) Analisa a Residência Onda Amarela, discutindo um repertório arquitetônico baseado não só em princípios de adequação térmica, mas também revela uma conexão com a linguagem vernacular da região, a casa indígena, conforme o quadro 1. 


\title{
Revista Científica ANAP Brasil
}

\author{
ISSN 1984-3240 - Volume 13, número 30, 2020
}

Quadro 1: Princípios bioclimáticos na residência Onda Amarela em Mosqueiro, Belém - Arq. Milton Monte.

\begin{tabular}{|c|c|c|c|}
\hline $\begin{array}{l}\text { Soluções } \\
\text { Projetuais }\end{array}$ & Casa Waiãpi & $\begin{array}{l}\text { Residência Onda } \\
\text { Amarela }\end{array}$ & Fotos da Residência Onda Amarela \\
\hline $\begin{array}{l}\text { Distribuição } \\
\text { dos espaços }\end{array}$ & $\begin{array}{l}\text { Espaço coberto na } \\
\text { frente da casa; } \\
\text { Os ambientes internos } \\
\text { não apresentam } \\
\text { divisórias. }\end{array}$ & $\begin{array}{l}\text { Inexistência de divisórias } \\
\text { entre a sala de } \\
\text { estar/jantar, cozinha e } \\
\text { mazanino; } \\
\text { Avarandado frontal } \\
\begin{array}{l}\text { conjugado ao estar e } \\
\text { separado por uma porta } \\
\text { de } 4 \text { folhas } \\
\text { constantemente aberta. }\end{array}\end{array}$ & \\
\hline Cobertura & $\begin{array}{l}\text { Material acessível; } \\
\text { Técnica de trançado } \\
\text { transferida de geração } \\
\text { para geração. }\end{array}$ & $\begin{array}{l}\text { Material de demolição } \\
\text { (telha francesa); } \\
\text { Resgata soluções do } \\
\text { homem da região; } \\
\text { Ático ventilado. }\end{array}$ & \\
\hline Beiral & $\begin{array}{l}\text { Curvo; } \\
\text { Consequência do } \\
\text { prolongamento da } \\
\text { cobertura, inclinação } \\
\text { acentuada, dimensão } \\
\text { também condicionada } \\
\text { à disponibilidade } \\
\text { material. }\end{array}$ & $\begin{array}{l}\text { Quebrado, conhecido } \\
\text { como quebra-sol/Quebra- } \\
\text { chuva; } \\
\text { Combate à insolação, às } \\
\text { chuvas e controle da } \\
\text { iluminação natural; } \\
\text { Localizado nas } \\
\text { orientações mais críticas. }\end{array}$ & \\
\hline Aberturas & $\begin{array}{l}\text { Em todo perímetro da } \\
\text { casa; } \\
\text { Quando não há } \\
\text { material suficiente } \\
\text { para os beirais longos, } \\
\text { a vedação é feita com } \\
\text { talas de paxiúba e as } \\
\text { aberturas se } \\
\text { restringem aos vãos de } \\
\text { acesso à casa. }\end{array}$ & $\begin{array}{l}\text { Vãos de janelas e portas } \\
\text { são vedados com } \\
\text { esquadrias móveis, } \\
\text { inclusive com bandeiras } \\
\text { vazadas; } \\
\text { As aberturas fixas são } \\
\text { decorrentes de tijolos } \\
\text { invertidos, } 1 / 2 \text { vez, uso de } \\
\text { peças de madeira } \\
\text { espaçadas. }\end{array}$ & \\
\hline $\begin{array}{l}\text { Nível do } \\
\text { piso }\end{array}$ & $\begin{array}{l}\text { Suspenso do solo por } \\
\text { motivos de segurança } \\
\text { e acentuar a sensação } \\
\text { de frios (ventos). }\end{array}$ & $\begin{array}{l}\text { Elevado para evitar o } \\
\text { contato com o solo } \\
\text { úmido; } \\
\text { Melhoria de ventilação } \\
\text { natural. }\end{array}$ & \\
\hline $\begin{array}{l}\text { Apropriação } \\
\text { dos espaços } \\
\text { pelos } \\
\text { usuários }\end{array}$ & $\begin{array}{l}\text { A maioria das } \\
\text { atividades se dá fora } \\
\text { da casa. No interior, } \\
\text { refeição e descanso. }\end{array}$ & $\begin{array}{l}\text { Espaço de convivência e } \\
\text { de maior permanência é } \\
\text { o avarandado. }\end{array}$ & \\
\hline
\end{tabular}

Fonte: Perdigão (1997). 
A inspiração com a morada indígena e com o barracão seringalista está presente nas obras do Arquiteto Milton Monte com a manifestação na arquitetura de aspectos socioculturais da região, conforme a Figura 4.

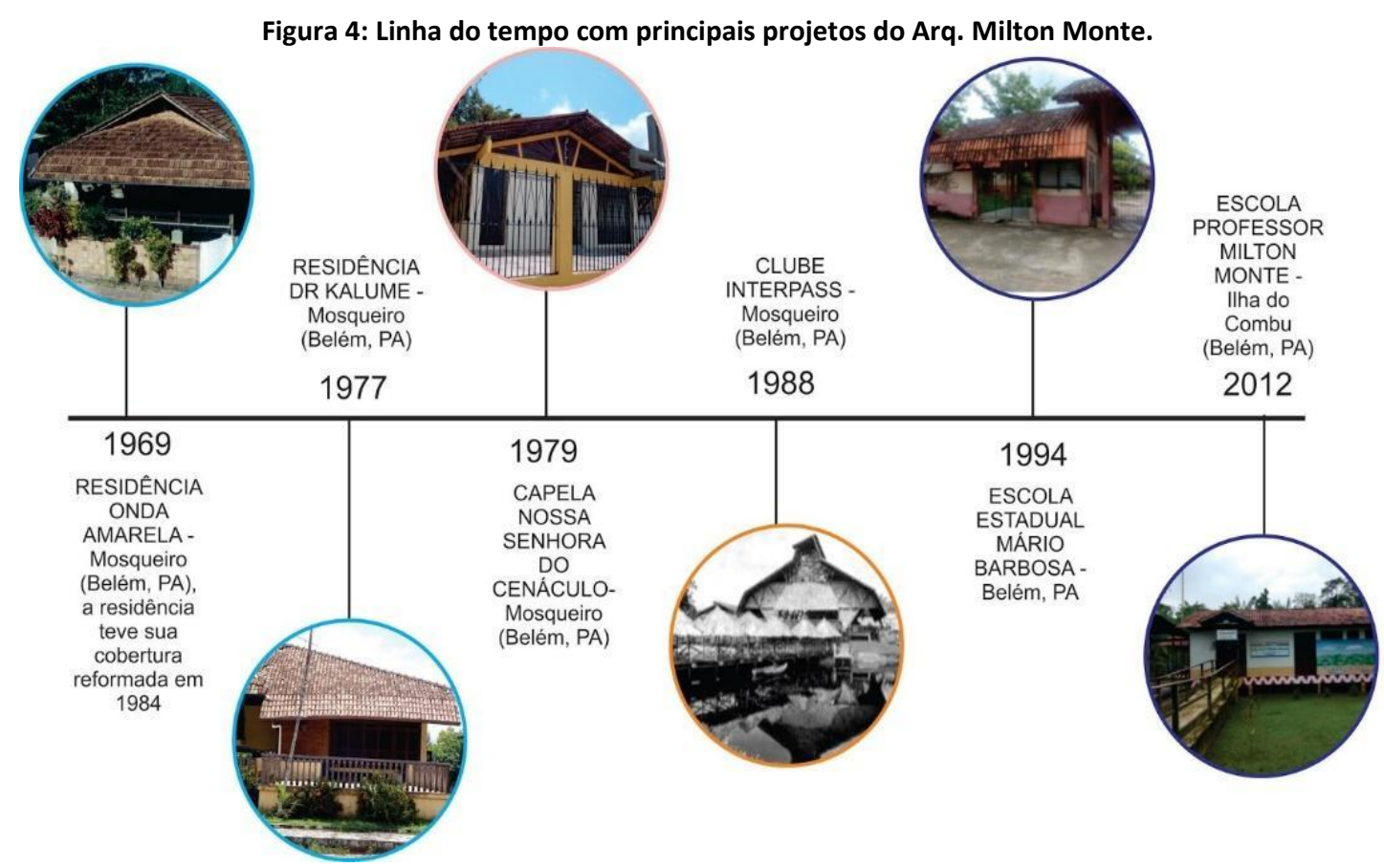

Fonte: Elaborado pelos autores

Perdigão et al (2018) constatam que a expressão do Arq. Monte sobre seu modo de projetar demonstra clareza e transparência de princípios, conforme preconiza a caixa de vidro citada por Silva (1986) ao se referir à transmissibilidade de conhecimento sobre a concepção do projeto de arquitetura. Trata-se de uma arquitetura projetada mediante as condicionantes climáticas, táteis e visuais do território, valida uma arquitetura com os recursos de seu tempo, utilizando analogias com a produção do espaço vernacular amazônico.

A residência Onda Amarela, residência de veraneio do Arq Milton Monte, localizada a $53 \mathrm{Km}$ da capital paraense, incorpora elementos relacionados aos princípios bioclimáticos da Amazônia, ao mesmo tempo em que incorpora soluções projetuais baseadas em tipologias vernaculares (ver figuras 1 e 2), apresentando relação estreita com padrões culturais vernaculares do interior da floresta, portanto, um vínculo com a realidade regional amazônica sem precedentes.

A residência prioriza determinadas soluções projetuais (ver figura 5); como divisórias que não seguem até o forro, paredes externas com partes vazadas em madeira ou em tijolos, beiral quebrado, varandas, sistema construtivo misto (madeira/alvenaria e concreto), ático ventilado, esquadrias com bandeiras vazadas e elevação do piso do nível do solo (PERDIGAO, 1997). Essas soluções eram usadas em conjunto e qualificam a produção de Milton Monte. Com relação ao beiral quebrado, utiliza um novo sistema de encaixe para estabilizar esforços devido ao dimensionamento generoso das peças de madeira. Diferente do sistema usado na Residência Kalume em 1997, com sistemas de tração e compressão para vencer um vão de 3,5m. 


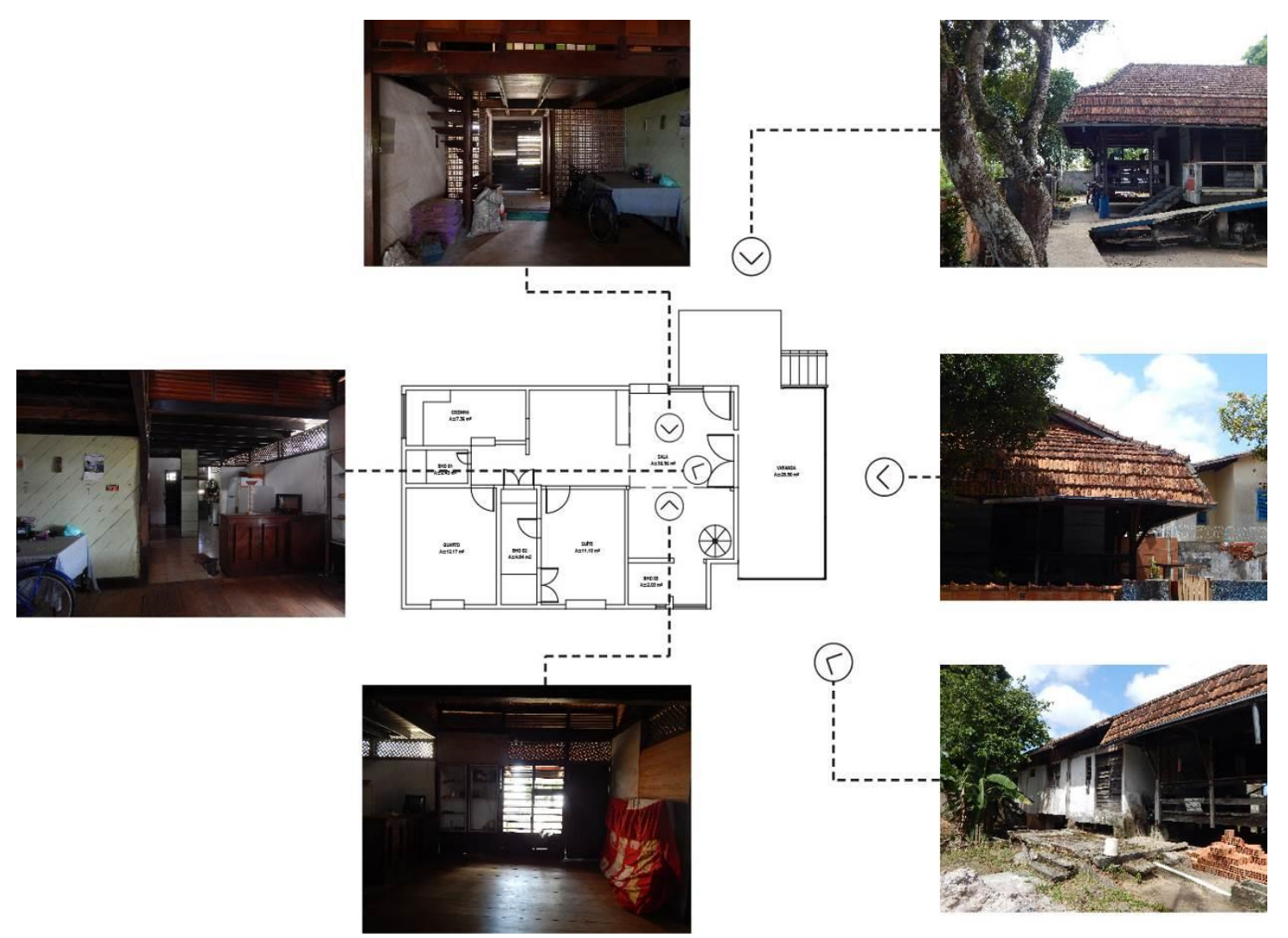

Fonte: Oliveira, $2018^{1}$ - acervo LEDH.

A Residência Onda Amarela de Milton Monte pode ser representada por sistemas que se interrelacionam e a descrevem (ver quadro 2); A primeira leva em conta a condição climática, o lugar no projeto. A segunda esfera é o sistema de referência que ele utilizava - a sua memória afetiva e a busca pelo espaço vernacular amazônico para soluções de problemas locais, bem como em referências da cultura formal internacional moderna. Pode-se apontar o papel do programa, da utilização dos espaços, como uma terceira esfera.

Esquema desenvolvido e apresentado no relatório de pesquisa da bolsista Leonice Farias de Oliveira (PIBIC 2018-2019) do Laboratório Espaço e Desenvolvimento Humano - LEDH/UFPA intitulado "Análise e interpretação de projetos residenciais do Arq. Milton Monte no contexto amazônico: olhares entre arquitetura erudita e não erudita", sob orientação da Profa Ana Klaudia Perdigão. 


\section{Revista Científica ANAP Brasil}

ISSN 1984-3240 - Volume 13, número 30, 2020

Quadro 2: Sistemas de descrição da concepção arquitetônica do Arquiteto Milton Monte

\begin{tabular}{|c|c|c|}
\hline SISTEMA DE SOLUÇÕES PRPOJETUAIS & SISTEMA DE REFERÊNCIAS & SISTEMA FUNCIONAL \\
\hline $\begin{array}{l}\text { Elevação do piso; } \\
\text { varanda } \\
\text { beiral quebra sol/quebra chuva } \\
\text { pátios cobertos; } \\
\text { cobertura cerâmica } \\
\text { ático ventilado }\end{array}$ & $\begin{array}{l}\text {-Morada Indígena; } \\
\text { - Barracão (cultura ribeirinha); } \\
\text {-Cidade natal no Seringal } \\
\text { (Acre); } \\
\text {--Arquitetura Moderna } \\
\text { (publicações internacionais). }\end{array}$ & $\begin{array}{l}\text {-Distribuição e utilização } \\
\text { dos espaços; } \\
\text {-demanda dos clientes; } \\
\text {-setorização } \\
\text {-relação interior/exterior } \\
\text {-ventilação cruzada, } \\
\text { esquadrias e forros }\end{array}$ \\
\hline
\end{tabular}

Fonte: elaborado pelos autores

O Quadro 2 com os sistemas de descrição da concepção da Residência Onda Amarela foi elaborado em decorrência da interpretação feita sobre um material do próprio Arquiteto Milton Monte, referente ao projeto de outra residência, a Gadotti. Trata-se um material precioso que reforça a compreensão sobre os sistemas adotados pelo Arq. Monte em seus projetos (ver figura $6)$.

Esse material foi encontrado num envelope com três sessões; a primeira relacionada às possíveis referências adotadas, a segunda relacionada ao projeto com seu esquema em vista superior e em vista frontal; essa segunda muito importante para o entendimento da estrutura e da forma da cobertura; contendo explicações sobre a estrutura da cobertura e destacando a presença do beiral quebrado. Logo após, a terceira sessão apresenta o resultado formal final e uma visualização real das estratégias adotadas e das decisões sintetizadas no partido arquitetônico.

Figura 6: Material do projeto da Casa Gadotti, encontrado em acervo de Monte.

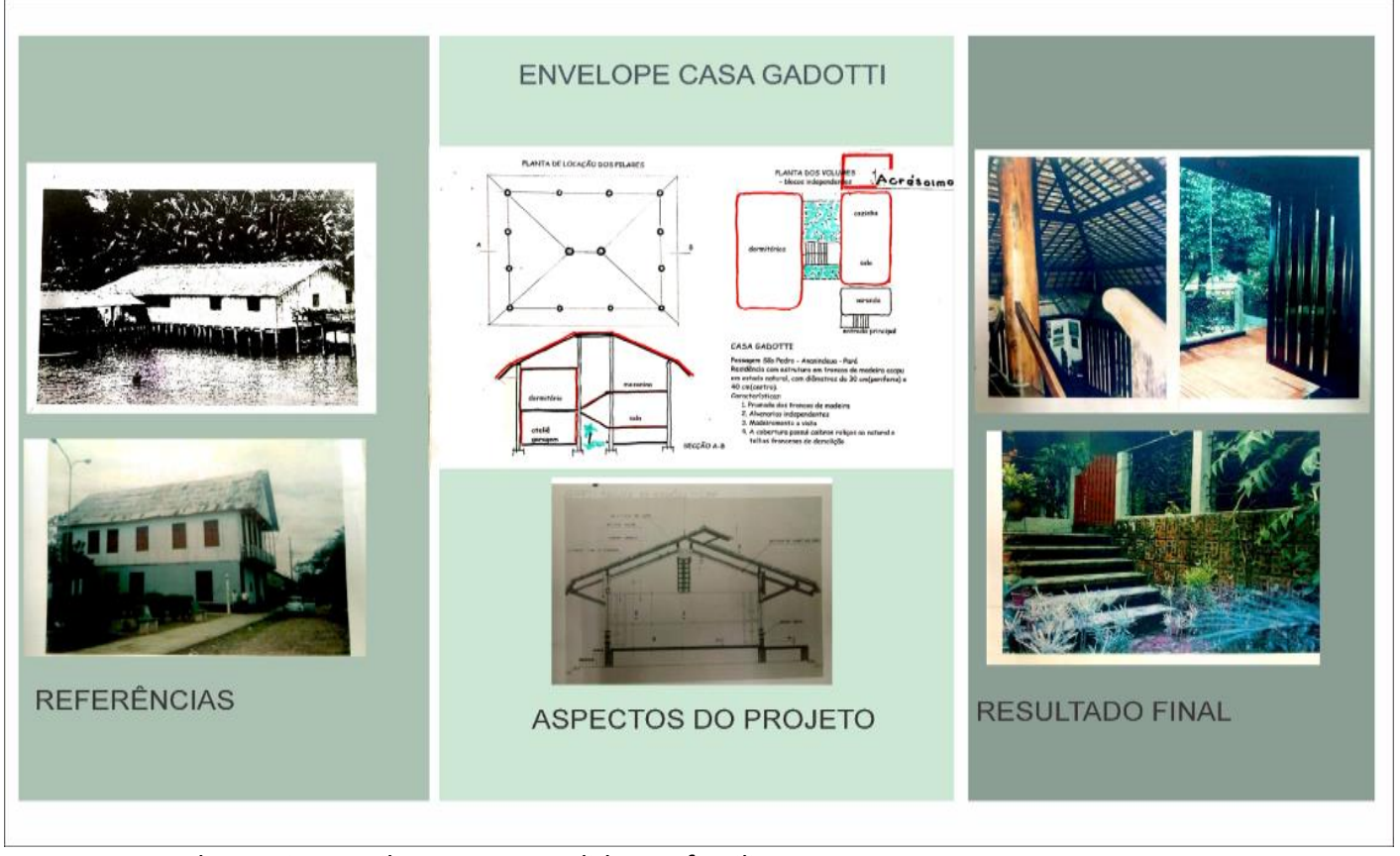

Fonte: Acervo do arquiteto Milton Monte, cedido por familiares.

\section{CONCLUSÕES}

O estudo das residências projetadas pelo Arq. Monte revela um pensamento projetual envolvendo um método racional que demonstra clareza de ideias e ações, baseado em 


\title{
Revista Científica ANAP Brasil
}

\author{
ISSN 1984-3240 - Volume 13, número 30, 2020
}

princípios e referências bem marcados para a concepção arquitetônica, e, revelando também, seu compromisso com uma arquitetura que reflete aspectos ambientais e culturais da Amazônia.

Os esquemas apresentados sobre sua obra e seu pensamento projetual, fazem transparecer a proximidade entre produção de arquitetura erudita e não erudita nos sistemas adotados pelo Arq. Milton Monte na elaboração de seus projetos de arquitetura, comprovando as referências e princípios adotados que permitem a observação do respeito ao lugar amazônico e ao programa como inspiração para o atendimento de seus clientes com a solução arquitetônica. As demandas locais podem ser utilizadas não como problemas a serem ignorados, mas como oportunidades de se observar como culturalmente elas são resolvidas, servido como fonte analógica e técnica.

Percebeu-se que a trajetória de Monte pode ser objeto de estudo para que a formação do arquiteto seja enriquecida com a cultura do lugar, contribuindo também com novos modos de pensar e de atuar na profissão. Outro questionamento que se mostra recorrente é a medida no uso da tradição no ofício da profissão. Assim sendo, a abordagem de uma sustentabilidade arquitetônica baseada na lógica conceitual eco-cultural mostra-se pertinente para caracterizar a produção arquitetônica do Arq. Milton Monte como um elo entre sua história de vida amazônica e sua atuação profissional.

O processo projetual utilizado por Monte em sua vasta experiência profissional resultou na sistematização de decisões projetuais pautadas por sistemas abrangentes que acompanham a concepção arquitetônica com vocabulário arquitetônico eminentemente amazônico. Sua trajetória profissional é uma obra viva que funciona como uma ferramenta de referência para processos analógicos que não ignorem a conexão entre projeto e lugar, produzindo uma arquitetura baseada também em modelos locais e não puramente sendo uma transposição de modelos internacionais de forma acrítica.

A contribuição profissional e acadêmica do Arquiteto Milton Monte inaugurou um lugar de estaque para uma região única no mundo e de forte afirmação cultural na produção de arquitetura local. É uma obra que ainda merece investigação pela riqueza de detalhes e de significados que oferece, e assim trazer visibilidade a um arquiteto que enfrentou uma contracorrente para implantação de uma arquitetura pulsante e peculiar na Amazônia.

\section{AGRADECIMENTO}

Como esse artigo é parte de uma das sínteses obtidas com base no plano de pesquisa 0 conhecimento operativo implícito na trajetória do arquiteto e professor Milton Monte para Amazônia, prestam-se agradecimentos à professora orientadora Ana Klaudia de Almeida Viana Perdigão, à equipe do Laboratório espaço e Desenvolvimento Humano (LEDH-UFPA) e aos familiares do professor Milton Monte que permitiram acesso a documentos importantes para a pesquisa e consequentemente para esse artigo. Prestam-se agradecimentos ao PIBIC da PROPESP-UFPA pela bolsa de pesquisa científica concedida, graças a qual foi possível maior dedicação ao desenvolvimento da pesquisa. 


\title{
Revista Científica ANAP Brasil
}

\author{
ISSN 1984-3240 - Volume 13, número 30, 2020
}

\section{REFERÊNCIAS}

CHUPIN, Jean-Pierre. As Três Lógicas Analógicas do Projeto. In: LARA, Fernando; MARQUES, Sonia (Org.). Projetar: Desafios e conquistas da pesquisa e do ensino de projeto. Rio de Janeiro: EVC. 2003. P. 11-32.

CLUBE DE ENGENHARIA DO PARÁ. Milton Monte - o Engenheiro Civil e Arquiteto: Caderno de anotações de sua vida profissional. 1990. 24p.

COMAS, Carlos Eduardo Dias (org). Projeto Arquitetônico, Disciplina em Crise, Disciplina em Renovação. São Paulo. Projeto. 1986.

FRAMPTON, Kenneth. Perspectivas para um Regionalismo Crítico. In: NESBITT, Kate (Org.). Uma nova agenda para a arquitetura. Antologia teórica (1965-1995). São Paulo, Cosac Naify. 2006. P. 503-520.

FRAMPTON, Kenneth. Regionalismo crítico: arquitetura moderna e identidade cultural. In: História crítica da arquitetura moderna. São Paulo, Martins Fonte. 2003. P. 381-397.

GRAEFF, Edgar. Reflexões de parceria e cultura. In: Revista projeto edição 135, outubro. São Paulo. Projeto editores associados Ltda. 1990. P. 104-106.

KOWALTOWSKI, D.; BIANCHI, G.; PETRECHE, J. R. D. A criatividade no processo de projeto. In: Kowaltowski, D.; Moreira, D.; Petreche, J. R. D.; Fabricio, M. M. (Org.). O processo de projeto em arquitetura - da teoria à tecnologia. São Paulo: Oficina de textos. 2011. P. 21-56.

MAHFUZ, E. C. A Reflexões Sobre a Construção da Forma Pertinente In: LARA, Fernando; MARQUES, Sonia (Org.). Projetar: Desafios e conquistas da pesquisa e do ensino de projeto. Rio de Janeiro: EVC. 2003. P. 64-81.

MAHFUZ, E. C. Como as partes são geradas. In: Ensaio Sobre a Razão Compositiva: Uma investigação sobre a natureza das relações entre as partes e o todo na composição arquitetônica. - Viçosa: UFV, impr. Univ.; Belo Horizonte: AP cultural. 1995. P. 69-115.

MIRANDA, Cybelle Salvador; CARVALHO, Ronaldo Marques de; TUTYIA, Dinah Reiko. Uma Formação em Curso: esboços da graduação em arquitetura e urbanismo da UFPA. Belém. Universidade Federal do Pará. 2015. Disponível em: https://issuu.com/lamemofauufpa/docs/uma forma o em curso. Acesso em: Setembro de 2018.

MONTE, José Milton Pinheiro. Estudos e contribuições sobre modelos de projetos e edificações na Amazônia Equatorial. 1986. 61f. Monografia (Especialização em Arquitetura nos Trópicos).

NORBERG-SCHULZ, C. O fenômeno do lugar. Uma Nova agenda para a arquitetura. São Paulo: Cosac \& Naify, p. 441-461, 2006.

OLIVEIRA, Ana Rosa de. Centro Cultural Jean Marie Tjibaou em Nouméa. Renzo Piano e a construção de um símbolo da civilização kanak. Arquitextos, São Paulo, ano 06, n. 063.01, Vitruvius, set. 2005. Disponível em: https://www.vitruvius.com.br/revistas/read/arquitextos/06.063/431. Acesso em Janeiro de 2020.

OLIVEIRA, Leonice Farias. Análise e interpretação de projetos residenciais do Arq. Milton Monte no contexto amazônico: olhares entre arquitetura erudita e não erudita. Relatório de pesquisa - Universidade Federal do Pará. Belém, PA. 2018.

PERDIGÃO, Ana Klaudia de Almeida Viana. Beiral quebra-sol/quebra-chuva: um estudo comparativo da resposta térmica no ambiente construído em zonas equatoriais úmidas, 1994. Dissertação de Mestrado - Universidade de São Paulo. São Paulo. 1994.

PERDIGÃO, A. K. A. V. Considerações sobre o tipo e seu uso em projetos de arquitetura. Arquitextos. Ano 10, nov. 2009. Disponível em: https://www.vitruvius.com.br/revistas/read/arquitextos/10.114/14 - Acesso em agosto de 2020.

PERDIGÃO, Ana Kláudia de Almeida Viana. Princípios bioclimáticos consolidados num modelo de arquitetura em Belém (PA). In: ENCONTRO NACIONAL SOBRE EDIFICAÇÕES E COMUNIDADES SUSTENTÁVEIS, 1.1997, Canela, RS. Anais, Canela, RS. 1997. P.197-202. PERDIGÃO, A.K.A.V. projeto cognitivo: uma abordagem do ensino de projeto 


\title{
Revista Científica ANAP Brasil
}

\author{
ISSN 1984-3240 - Volume 13, número 30, 2020
}

pelo interior da prática. VI SBQP: Projetar para quem? Desafios locais frente às mudanças globais. Uberlândia. 2019. P. $1588-1598$

PERDIGAO, A. K. A. V; OLIVEIRA, L. F; LADEIA, D. C. Milton Monte e sua Arquitetura do Barracão: análise da residência Onda Amarela, Ilha do Mosqueiro (PA). In: III SAMA: Seminário de Arquitetura Moderna na Amazônia. Belém. 2018.

RABELO, Eloíse Mendes. Análise e interpretação de projetos de escolas do Arq. Milton Monte no contexto amazônico: olhares entre a arquitetura erudita e não erudita. Relatório de pesquisa - Universidade Federal do Pará, Belém, PA. 2019.

REIS-ALVES, Luiz Augusto dos. 0 conceito de lugar. Arquitextos. São Paulo. Ano 08, n. 087.10. Vitruvius, ago. 2007. Disponível em: https://www.vitruvius.com.br/revistas/read/arquitextos/08.087/225. Acesso em Set. de 2019.

ROSSI, Aldo. Uma arquitetura analógica. In: NESBITT, Kate (Org.). Uma nova agenda para a arquitetura. Antologia teórica (1965-1995). São Paulo. Cosac Naify. 2006, P. 377-384.

SANTOS, Soraia Costa do; COSTA, Silvia Kimo. ARQUITETURA VERNACULAR OU POPULAR BRASILEIRA: CONCEITOS, ASPECTOS CONSTRUTIVOS E IDENTIDADE CULTURAL LOCAL. Cadernos de Arquitetura e Urbanismo v. 24, n. 35,20 sem. 2017. P. 218-258.

SEGAWA, Hugo. Fitomorfia amazônica, o restaurante de João Castro Filho. In: Revista projeto edição 169, novembro. São Paulo. Projeto editores associados Ltda. 1993. Pg. 36-41.

SEGAWA, Hugo. Tropicalismo o barbárie. In: .Arquitectura latinoamericana contemporánea. Barcelona, Espanha: Gustavo Gili. 2005. cap.no4, p.83-99.

SILVA, Elvan. Arquitetura e Cultura vernácula. In: Matéria, Ideia e Forma: Uma definição de arquitetura. Porto Alegre: Ed. Universidade/UFRGS. 1994.

SILVA, Elvan. Novos e Velhos Conceitos no Ensino de Projeto Arquitetônico. In: LARA, Fernando; MARQUES, Sonia (Org.). Projetar: Desafios e conquistas da pesquisa e do ensino de projeto. Rio de Janeiro: EVC. 2003. P. 32-35.

SILVA, Elvan. Sobre a Renovação do Conceito de Projeto Arquitetônico e sua Didática. In: COMAS, Carlos Eduardo Dias (org). Projeto Arquitetônico, Disciplina em Crise, Disciplina em Renovação. São Paulo. Projeto. 1986. P.15-31.

SILVA, Elvan. Uma introdução ao projeto arquitetônico. Porto alegre. Editora da UFRGS. 1ª edição. 1984.

ZEIN, Ruth Verde. A Síntese Como Ponto de Partida e Não de Chegada. In: LARA, Fernando; MARQUES, Sonia (Org.). Projetar: Desafios e conquistas da pesquisa e do ensino de projeto. Rio de Janeiro: EVC. 2003. P. 32-35. 